\title{
Research on the New Model of Education Precision Funding under the Model of Precision Poverty Alleviation
}

\author{
Haixia Yang * \\ Chongqing Normal University, Chongqing 40047, China.
}

\begin{abstract}
In recent years, the precision funding of college students with financial difficulties has been increasing. Doing a good job of "precision funding" for impoverished college students has become an important task of "funding poverty alleviation" in colleges and universities. This article elaborates on the problems of current poverty-stricken college students' financial aid work under the concept of targeted poverty alleviation and college students' precise financial aid, and analyzes the practice path of "accurate financial aid" for impoverished college students.

Keywords: Targeted poverty alleviation; Education; Targeted funding
\end{abstract}

\section{Overview of targeted poverty alleviation}

"Precision poverty alleviation" was put forward by General Secretary during his inspection in Xiangxi in 2013. He pointed out: "Poverty alleviation must be realistic and appropriate to local conditions. Targeted poverty alleviation." This idea was also issued in 2015 by the State Council The "Decision" is further explained, "Insist on targeted poverty alleviation, improve the effectiveness of poverty alleviation, and achieve true poverty alleviation, true poverty alleviation, and true poverty alleviation ${ }^{[1]}$." The idea of

Copyright (C) 2020 Haixia Yang

doi: $10.18282 / 1-$ e.v9i4.1688

This is an open-access article distributed under the terms of the Creative Commons Attribution Non-Commercial License (http://creativecommons.org/licenses/by-nc/4.0/), which permits unrestricted non-commercial use, distribution, and reproduction in any medium, provided the original work is properly cited.

The government issued normative documents to promote the establishment of the normal mechanism of intangible cultural heritage "entering the campus", clarifying the guiding ideology, work content, implementation methods, working mechanism and division of responsibilities, integrating cultural, educational and social resources, and carrying out overall planning and overall coordination from the system and mechanism.

Establish evaluation mechanism

Chinese traditional culture is broad and profound. There are many kinds of items and rich contents. We should establish a review mechanism, organize experts and scholars from many disciplines such as social sciences, culture and education to set up a variety of professional review committees, sort out and review the intangible assets into the campus resources, identify the real resources before entering the campus, extract the essence, and remove the dross, so as to ensure the healthy and excellent cultural content of the campus. Show and apply.

Improve the security mechanism

It is suggested to set up an organization and coordination organization led by the education and culture departments and participated by relevant departments to jointly promote the implementation of Intangible Cultural Heritage Inheritance "into campus", and provide necessary financial support. Make full use of cultural venues, intangible cultural heritage heritage base, red tourism base, historical and cultural cities and towns and other cultural places to establish intangible cultural heritage campus practice base and carry out students' learning and experience activities. The evaluation mechanism should be established to evaluate the performance of the activities of cultural and educational departments at all levels to promote the inheritance of intangible cultural heritage.

\section{Reference}

[1]ZHANG Zhaolin. Intangible cultural heritage theme IP: the symbiotic relationship between inheritance, activation and current young audience groups[J]. Art Research,2020(06):122-125.

[2]ZHU Run, FENG Xiaojuan. Construction and exploration of inheritance practice base of intangible cultural heritage in Colleges and Universities[J]. Laboratory Research and Exploration, 2019,38(11):270-273.

[3]JING Qiao, GAI Haihong, WANG Jingmin. Feasibility study on the integration of Hebei intangible cultural heritage and university curriculum[J]. Journal of Hebei Normal University (EDUCATION SCIENCE EDITION), 2010,12(03):126-128.

[4]LI Yang. Research on innovation mode of intangible cultural heritage tourism resources based on digital platform[J]. Packaging Engineering, 2015,36(10):32-35.

[5]YUAN Li, GU Jun. Intangible cultural heritage[M]. Beijing: Higher Education Press,2009 
precise poverty alleviation means that the work of poverty alleviation is not just a slogan, but the party Solemn promises made by the people across the country. It is of great epoch-making to put forward the idea of targeted poverty alleviation in the sprint stage of building a well-off society in an all-round way ${ }^{[2]}$. Contrary to extensive poverty alleviation, targeted poverty alleviation emphasizes accuracy in the policy formulation and implementation stages. It is necessary to target the impoverished areas and the poor population with accurate pulses and precise policies to ensure Effectiveness of poverty alleviation.

\section{The current bottleneck in college student funding}

\subsection{Inaccurate identification of difficult groups}

In the process of implementation of the funding of colleges and universities, in the process of implementation, in order to achieve full coverage of financial assistance for students in difficulty, they often ignore the detailed understanding or indepth distinction of the situation of the students, plus the civil affairs departments of each source of origin Confirming that the responsibility is not clear, under the premise of ensuring that the funding is in place, universities will inevitably lack accurate identification and definition of funding targets, ${ }^{[3]}$ and it is easy for the scope of funding to be large and comprehensive, which is more extensive and more inadequate. For students with particularly difficult families, school funding is like "scratching" and cannot solve the fundamental problem. Therefore, only by achieving accurate identification of difficult students and promoting the refinement of subsidy work can we further improve the subsidy work for college students ${ }^{[4]}$.

\subsection{Inaccurate assistance measures}

The main causes of poverty of students with family financial difficulties and family background are different, their needs for subsidies will be different; and the same students in different grades or in different stages, their individual needs also differ. However, for individual students or groups of financially difficult students in different categories or different periods, there is little empathy in the funding work of colleges and universities ${ }^{[5]}$, lack of innovative ideas, lack of personalization and refinement of funding work, often neglecting the differences in needs of various groups of students with difficulties. Aid lacks dynamic analysis, the work form is not rich enough, and the work objective is too utilitarian. This kind of subsidy is easy to cause the "supply and demand" of the subsidy work to be uncorresponding, and the accuracy is poor. The good opportunity makes the effect of subsidies greatly discounted.

\subsection{Mental poverty to be resolved}

The funding work of colleges and universities has always been concentrated on the level of financial aid. It attaches importance to solving the financial difficulties of students with national and various social funds, and it is easy to ignore the shaping and support of the mental level of difficult students and the psychological guidance after receiving assistance. Students with family difficulties are often more sensitive, the sense of belonging is more difficult to establish, the psychological gap and pressure are relatively large, the social skills are relatively weak, and the comprehensive quality needs to be improved. The practical problems are difficult to solve with pure material support. Some of the assisted students have serious ideology of "waiting, relying, and asking", lacking the consciousness of self-reliance and self-reliance, and lacking the consciousness of giving thanks to the society. The humanistic care and education demands of the subsidy work itself have been weakened, making it difficult for students to experience life fundamentally. Satisfaction cannot achieve "mental poverty".

\section{Education under the model of targeted poverty alleviation}

\subsection{Accurate identification lays a solid foundation for education funding}

(1) Formulate scientific and reasonable recognition standard procedures. First, relying on modern information technology methods to widely collect information such as students' family status and personal consumption data, analyze various information, and identify the authenticity of student application materials. Second, a comprehensive analysis of the students' family income, personal consumption, family members, and economic development of the family's location, etc., and a scientific and reasonable group suitable for the primary identification group such as class or grade should be developed under the identification standards prescribed by the school. Criteria for identifying difficulty levels ${ }^{[6]}$. Third, strengthen the dynamic management of students in difficulty, establish a flexible access mechanism, in addition to the annual identification work, use daily information to sort out and judge the situation of students in difficulty, and complete the update of the difficulty database in a timely manner.

(2) Use big data to obtain accurate and comprehensive data. Introducing big data into the field of university funding can mine student information through various channels, such as family economic income status, family member status, student daily consumption level, student moral cultivation, etc., expand information coverage, improve information utilization, and build more To provide a comprehensive information database and provide accurate and basic data for difficult identification. For example, many colleges and universities have loopholes in the identification of difficulties, and many students who are deemed to be in financial difficulty when they enter the school have been receiving subsidies for subsidies during the school period, resulting in the fact that many new students in difficulty cannot be identified and thus cannot receive funding. Using big data analysis technology, you can find students who actually have difficulties but have not applied, or students who have improved family economic conditions but are still enjoying subsidies to achieve accurate identification ${ }^{[7]}$.

\subsection{Accurate help grasp the core of precise education funding}

The core of precision funding lies in the implementation of policies. How to carry out precision assistance according to the actual needs of students plays a decisive role in the effectiveness of funding. Therefore, precision funding should be transformed from guaranteed funding to developmental funding, and gradually expanded from economic assistance to psychological, adaptation, 
interpersonal, emotional, ideological, academic, employment, and other combined measures.

First, make sure that you understand the symptoms accurately. Colleges and universities should establish a card for each student with financial difficulties and follow up management. In addition to finding out the financial situation of the students' families, they should also fully understand the students' growth experience, parent-child relationship, and actual needs to ensure that they fully understand the students.

Second, we must provide accurate forms of assistance, provide students with various means of funding in an appropriate and most needed way, and truly achieve "point-to-point" assistance. For example, Wuhan University of Technology has established a multi-level "self-improvement society" student club organization, which has achieved good results in freshmen's adaptive activities, psychological assistance, academic mutual assistance, and voluntary service to the society.

Third, it is necessary to achieve precise assistance measures and highlight the timeliness and pertinence of development-based funding. Such as: providing psychological counseling services for students with psychological and social difficulties caused by economic difficulties, providing overseas exchange opportunities for students who have the desire to study abroad, and providing employment guidance for students who need employment. Under the guidance of the concept of precision poverty alleviation, the school level attaches importance to and supports precision funding, strengthens collaboration among various departments of universities, and jointly builds a three-dimensional precision funding system.

\subsection{Trusting people to improve the effectiveness of subsidized education}

The "five in one" funding system can be divided into two types: paid funding and unpaid funding, such as: scholarships, workstudy, etc. require labor, and student loans, interest-free loans, etc. that need to be repaid are paid funding, through the procedures of student loans and repayment, help students establish a concept of integrity and promote the spirit of contract. At the same time, we should use student platforms, student activities and other platforms to carry out education and self-education activities to cultivate students' sense of responsibility, gratitude and dedication. Complete all kinds of subsidy work with the work concept of elaborate educating people, continuously improve the effect of educating people and enhance the effectiveness of precise subsidy

\section{Conclusion}

Driven by the targeted poverty alleviation policy, the poverty alleviation work of college students has made great progress, but there are still many omissions on some issues. For example, there are subjective problems in the assessment standards of college poor students, which proves the lack of authenticity of the materials. The rules and standard principles are not perfect, etc., through a series of scientific funding methods to carry out poverty alleviation work for college students, and promote students to truly develop and change their own destiny.

\section{References}

[1]Alam K R . Ganokendra: An Innovative Model for Poverty Alleviation In Bangladesh[J]. International Review of Education, vol. 52, no. 3, pp. 343-352, 2016.

[2]Ping-Hua F . Reducing poverty and education development:the accuracy of a participatory governance perspective for poverty alleviation[J]. Journal of Guizhou University of Finance and Economics, vol. 28, no. 1, pp. 527-529, 2017. 